\title{
A propósito del SARS CoV 2/ COVID 19 ¿Qué hemos aprendido de las pandemias?
}

\section{Taking into account the current SARS COV 2 / COVID19 situation in the world, What have we learned from pandemics?}

\author{
Virginia Rodríguez Rodríguez'
}

La historia de la humanidad ha estado marcada por devastadoras epidemias, muchas veces ocasionaron más muertes que las que se generaron en las guerras. Los conceptos de su origen, prevención y manejo han ido cambiando, atrás quedaron las creencias ancestrales de su origen mitológico, divino, un dios enfadado que al ver que su pueblo quebranta el programa de vida trazado decide castigarlo. Tucídides en la historia de la guerra del Peloponeso (428 A.C), documentó la Peste de Atenas con graves consecuencias económicas y estratégicas como la muerte de más 5.000 pobladores, 12.000 soldados e incluso con la muerte de Pericles. Imperios como el Romano en algunos momentos se beneficiaron de las pestes como por ejemplo cuando el ejército cartaginés fue asolado por la Peste de Siracusa, permitiendo una fácil derrota por el ejército romano (396 AC); otras epidemias como: Peste Antonina y la Peste Justiniana contribuyeron al declive del imperio Romano (1).

La epidemia de la Peste Negra (1347 a 1350), las variantes de Peste Neumónica, Peste Septicémica y sus reinfecciones azotaron a la mayor parte del continente europeo, resultaron casi siempre mortales y ocasionaron grandes cambios en la población como despoblamiento, baja en rentas públicas, abandono de las labores del campo, destierros, éxodo hacia ciudades, fallecimiento de notarios, juristas, religiosos y médicos, muertes ocasionadas por estrecho contacto con enfermos; todo esto agravó la crisis económica y social que vivió Europa desde mediados del siglo XIV. Ante los fracasos de los remedios populares (quemas de incienso y aromas e introducción de hierbas exóticas del nuevo mundo) las ciudades comenzaron a implementar las primeras medidas sanitarias que incluyeron el aislamiento de enfermos, quemas de vestimentas, cuarentenas a barcos y los médicos adoptaron trajes especiales para protegerse del contagio (1).

Londres, sufrió tres severas epidemias de cólera en 1832, 1848-1849 y 1853-1854, fue el médico John Snow uno de los fundadores de la epidemiología, quien, utilizando un meticuloso sistema de mapeo de los casos, mostró como se transmite el cólera (2), sentó las bases teórico-metodológicas de la epidemiología que a través de los tiempos se ha utilizado para investigar las causas y estrategias de control de las enfermedades transmisibles.

1 Bacterióloga. M.Sc. en Microbiología. Grupo de Investigaciones Microbiológicas y Biomédicas de Córdoba (GIMBIC), Programa Bacteriología Universidad de Córdoba. Correspondencia: vrodriguez@correo.unicordoba.edu.co
Citación (Vancouver): Rodríguez V. A propósito del SARS CoV 2/COVID 19 ¿Qué hemos aprendido de las pandemias?. (4)1 :6-10 . DOI: 10.21897/25394622.2034 
El virus de la influenza ocasionó varias pandemias a lo largo del siglo XX y a principios del siglo XXI. La gripe española, ocurrida entre 1918 y 1919 provocó más muertes que la primera guerra mundial. El momento histórico conllevó a la censura de la prensa y ocasionó la baja disponibilidad de información contribuyendo a que no se generará conciencia de la gravedad de la pandemia. Los adultos jóvenes fue el grupo poblacional de mayor riesgo y más afectada, no se pudo aislar por encontrarse en el frente de batalla (3). Estados Unidos fue el origen de la pandemia y documentó la implementación de medidas que incluyeron cierre de teatros, cines y escuelas nocturnas, prohibición de reuniones públicas, uso de máscaras y programas educativos para difundir publicidad acerca del peligro de toser y estornudar (4). La gripe española, señaló la necesidad de identificar de manera rápida el agente causal, caracterización clínica y epidemiológicamente de la enfermedad, lo que permitió enfocarse en estrategias de prevención, profilaxis y tratamiento eficaces para el control de su propagación. Entre 1957-1958 y en 1968, se produjeron dos pandemias consideradas leves por la OMS como: la gripe asiática, causada por un nuevo virus de la influenza A (H2N2), y la gripe de Hong Kong A (H3N2). Después de cuatro décadas en 2009 la OMS declaró una nueva pandemia de influenza A H1N1 (5).

Virus diferentes al de la influenza han generado diversas situaciones epidemiológicas de importancia en lo que va del siglo XXI. Epidemias de Ébola se han presentado en 2014, 2018-2020 y Zika en 2015-2016 (6). En las últimas dos décadas, han emergido tres coronavirus (CoV) que han provocado importantes enfermedades humanas de impacto en la salud global. Los CoV son patógenos importantes para humanos y animales vertebrados, que generalmente causan enfermedades leves (7), infectando sistemas como: respiratorio, gastrointestinal, hepático y nervioso central de humanos en ganados, aves, murciélagos, ratones y animales silvestres (8). Mutaciones en el gen que codifica para la glicoproteína $S$ presente en la envoltura de los coronavirus origina cambios estructurales que permiten la unión a nuevos receptores y el salto de especie animal a humano (9); lo anterior sumado al cambio climático, ecológico y el aumento de las interacciones de los humanos con animales abre la puerta para la transmisión de animales a humanos y de humanos a humanos de CoVs emergentes aumentando el riesgo de presentación de brotes que se perpetúan a gran escala y se convierten en epidemias y pandemias. El síndrome respiratorio agudo severo (SARS) en 2002/2003, el síndrome respiratorio del Medio Oriente (MERS) en 2012 y la nueva pandemia COVID 19 ocasionada por el SARS CoV-2, resaltan la importancia en salud pública de virus emergentes de origen zoonótico.

El SARS mostró que las organizaciones médicas y científicas no estaban preparadas adecuadamente para la aparición de virus altamente patógenos, varios meses transcurrieron antes de que el agente causal fuera identificado, el intercambio rápido y transparente de información entre países y comunidad científica no se dio en tiempo real. Con el desarrollo de tecnologías como la secuenciación de nueva generación el agente causal del MERS fue identificado antes de que causara un gran brote, la disponibilidad del genoma completo del MERS-CoV permitió un rápido desarrollo y distribución de ensayos de diagnóstico (10).

En caso del SARS-CoV y MERS-CoV se presentaron sintomatologías similares y varios factores de riesgo en común como: edad avanzada, sexo masculino y la presencia de comorbilidades; para el MERS fue: diabetes mellitus, hipertensión, cáncer, coinfecciones, enfermedad renal y pulmonar, todas estas se asociaron a un mal pronóstico. Las instituciones prestadoras de servicios de salud presentaron un mayor riesgo de transmisión viral, permitiendo ver que para futuros eventos de características similares las prácticas de higiene hospitalaria y las medidas de protección adecuada 
del personal de la salud limitarían la aparición de brotes nosocomiales y diseminación desde estos escenarios a la comunidad. Sin embargo, se presentaron importantes diferencias, en SARS entre el $20-30 \%$ de los pacientes requirieron cuidados intensivos con ventilación mecánica con una letalidad aproximada al 10\%; en comparación el MERS el 50-89\% de los pacientes requirió de cuidados intensivos y la tasa de letalidad estuvo alrededor del 36\% $(11,12)$. La letalidad bruta de los casos clínicos de SARS CoV 2. supera actualmente el 3\%, aunque aumenta con la edad hasta aproximadamente el 15\% o más en pacientes mayores de 80 años (13).

La COVID 19, ha originado una emergencia sanitaria, económica, social y ambiental a nivel mundial. En muy corto tiempo se ha convertido en pandemia con tres características definidas: rapidez-escala, gravedad y perturbación socioeconómica (13). A la fecha se reporta circulación en 180 países, aproximadamente 3,2 millones de casos y más de 231000 muertes. El 80\% de los contagiados experimenta síntomas leves similares a los de una gripe común o son asintomáticos, los casos severos acaban en neumonía y requieren de cuidados intensivos con ventilación mecánica. Los factores de riesgo asociados a severidad incluyen enfermedades subyacentes y edad avanzada. En tiempo récord (cuatro semanas) se identificó a un nuevo coronavirus como el agente causal (SARS CoV 2), se secuenció y se publicó su genoma, se desarrollaron pruebas diagnósticas (RT-PCR en tiempo real).

Se considera que, además de medidas de salud pública basadas en pruebas, se necesitan medios de diagnóstico, tratamientos y vacunas innovadoras para hacer frente a la COVID-19, en tiempo récord y a una escala y con unos niveles de acceso sin precedentes, la intención es salvar millones de vidas e incontables billones de dólares, y devolver al mundo a una situación de «normalidad». La lucha contra la COVID-19 es interdisciplinaria, nadie debe quedar atrás. La OMS como autoridad sanitaria internacional activó el Plan de Investigación y Desarrollo (6), un proyecto de colaboración sin precedentes, de carácter mundial y por un periodo de tiempo limitado, cuyo objetivo es acelerar en todo el mundo el desarrollo y la producción de nuevas tecnologías sanitarias esenciales para hacer frente a la COVID-19, así como el acceso equitativo a las mismas (13).

Un factor clave para controlar una amenaza emergente es el intercambio eficiente, transparente y en tiempo real de la información que permita el direccionamiento de estrategias de prevención y control. Las herramientas de comunicación actuales están permitiendo acceder a información muy valiosa en cortos periodos de tiempo y han sido el instrumento para difundir entre la población, las estrategias básicas de prevención que incluyen: lavado de manos, evitar tocarse la cara, buena higiene respiratoria y distanciamiento social entre otras. Sin embargo, la OMS no cuenta actualmente con un mecanismo armonizado de notificación de salud pública que permita el intercambio de información de los institutos y agencias de salud pública directamente a la OMS, constituyendo una barrera para el acceso a los datos desglosados, necesarios para comprender características epidemiológicas específicas (13).

Para contener la propagación de la COVID 19 se ha recurrido a la realización de pruebas diagnósticas con miras a lograr la entrega de resultados en un tiempo inferior a 24 horas, asegurando el establecimiento oportuno del cerco epidemiológico, permitiendo el aislamiento de los casos confirmados y garantizando su control médico intrahospitalario o intradomiciliario durante catorce días como mínimo, sujetos a la evolución clínica. Sin embargo, estas medidas dejan de lado los casos leves y asintomáticos, mostrando la necesidad de poner en marcha la realización de pruebas 
diagnósticas a gran escala para implementar las medidas de contención pertinentes (13).

La presentación de enfermedades zoonóticas emergentes, son el reflejo de la incesante lucha de los agentes causales por sobrevivir, buscando brechas en las barreras que protegen al ser humano contra la infección. Estas brechas sanitarias, que se han venido agrandando desde hace algunas décadas, pueden obedecer a comportamientos de alto riesgo como fallas en los sistemas de vigilancia epidemiológica, control inadecuado de los animales reservorios, o de los focos de transmisión de enfermedades, acercamiento de la fauna silvestre a los asentamientos humanos por la deforestación, entre otros (14).

Aunque estamos ante una nueva pandemia muchas de las estrategias implementadas corresponden a experiencias de eventos anteriores e incluso a las experiencias de países que por cronología les ha llegado primero este azote. Un gran número de países han optado por responder a esta emergencia en exceso para posteriormente reducir la escala de ser necesario. Esto ha traído consigo cierre temporal de aeropuertos y fronteras, la imposición de medidas de cuarentena por tiempos prolongados a sus habitantes, deteniendo la vida social y económica a pesar del efecto negativo que pueda tener especialmente sobre la población más vulnerable. Estos hechos no tienen precedente en la historia reciente de la humanidad y su impacto sólo va a ser mitigado a través del esfuerzo coordinado de las autoridades sanitarias y demás sectores de la sociedad. En la medida en que se propenda por acciones de solidaridad a nivel de cada país e internacionalmente, las estrategias de prevención primaria y secundaria servirían como complemento para el control del SARS CoV 2 en materia de salud colectiva.

\section{REFERENCES}

1. Las Primeras Epidemias de la Historia. [internet] Recuperado a partir de: http://www. sld.cu/galerias/pdf/sitios/bmn/las_primeras_epidemias_de_la_historia.pdf

2. Bynum WF. In retrospect on the mode of communication of cholera. Nature. 2013; 495:169-170. doi: https://doi.org/10.1038/495169a

3. Murillo GG. Recordando a la gripe española. Med Int Mex 2011;27(5):463-466. Recuperado a partir de: https://www.medigraphic.com/cgi-bin/new/resumen.cgi?lDARTICULO=31197

4. Centro para el Control de Enfermedades. Cronología histórica de la influenza pandémica de 1918. 2018. Recuperado a partir de: https://espanol.cdc.gov/flu/pandemic-resources/1918-commemoration/ pandemic-timeline-1918.htm

5. Saavedra Trujillo C. Consenso colombiano de atención, diagnóstico y manejo de la infección por SARS-COV-2/COVID 19 en establecimientos de atención de la salud. Recomendaciones basadas en consenso de expertos e informadas en la evidencia. Infectio. 2020;24(3):3-6. doi: http://dx.doi. org/10.22354/in.v24i3.851

6. Mehand MS, Al-Shorbaji F, Millett P, Murgue B. The WHO R\&D Blueprint: 2018 review of emerging infectious diseases requiring urgent research and development efforts. Antiviral Res. 2018;159:6367. doi: https://doi.org/10.1016/j.antiviral.2018.09.009

7. Mousavizadeh L, Ghasemi S. Genotype and phenotype of COVID-19: Their roles in pathogenesis [published online ahead of print, 2020 Mar 31]. J Microbiol Immunol Infect. 2020;.doi:10.1016/j.jmii.2020.03.022

8. Chen Y, Liu Q, Guo D. Emerging coronaviruses: Genome structure, replication, and pathogenesis. J Med Virol. 2020;92(4):418423. doi:10.1002/jmv.25681 
9. Dietz L, Horve PF, Coil DA, Fretz M, Eisen JA, Van Den Wymelenberg K. 2019 Novel Coronavirus (COVID-19) pandemic: Built environment considerations to reduce transmission. mSystems. 2020;5(2): e00245-20. doi:10.1128/mSystems.00245-20

10. McCloskey B, Heymann DL. SARS to novel coronavirus-old lessons and new lessons. Epidemiology and Infection. 2020;148, e22, 1-4. doi.org/10.1017/S0950268820000254

11. de Wit E, van Doremalen N, Falzarano D, Munster VJ. SARS and MERS: recent insights into emerging coronaviruses. Nature reviews. Microbiology. 2016;14(8):523-534. https://doi.org/10.1038/nrmicro.2016.81
12. Guarner J. Three emerging coronaviruses in two decades. Am J Clin Pathol. 2020;153(4):420-421. doi:10.1093/ajcp/ aqaa029

13. Organización Mundial de la Salud. Actualización de la estrategia frente a la covid-19.2020. Recuperado a partir de: https:// www.who.int/docs/default-source/coronaviruse/covid-strategy-update-14april2020 es.pdf?sfvrsn=86c0929d 10

14. Suárez LCL, Berdasquera CD. Enfermedades emergentes y reemergentes: Factores causales y vigilancia. Rev Cubana Med Gen Integr. 2000;16(6):593-597. 